\title{
ANALISIS PERENCANAAN WISMA FAKULTAS TEKNIK DENGAN PENDEKATAN ARSITEKTUR POST-MODERN ROBERT VENTURI DI UNIVERSITAS NEGERI MANADO
}

Rezky Natanael Tumundo ${ }^{1}$; Morris S.S.S. Tumanduk²; Rulyanto G.M. Lasut ${ }^{3}$; Metsi Daud ${ }^{4}$. Pendidikan Teknik Bangunan, Fakultas Teknik, Universitas Negeri Manado rezkynatanael33@gmail.com morris_tumanduk@unima.ac.id lrio@unima.ac.id mtsdaud@yahoo.co.id

\begin{abstract}
ABSTRAK
Tujuan perencanaan ini adalah untuk memusatkan kegiatan seminar, kunjungan kerja, penginapan dan kegiatan magang bagi mahasiswa serta bagi tamu pada umumnya dalam satu fasilitas yaitu Wisma. Metode perancangan yang digunakan dalam penelitian ini mengacu pada teori Metode Glass box JC. Jones didalamnya ada Analisis Makro, Analisis Mikro, Struktur dan Utilitas. Hasil dari perencanaan ini berupa desain bangunan yang ditampilkan dalam bentuk Site Plan, Denah, Potongan, Tampak dan Perspektif bangunan. Kesimpulan dari perencanaan Wisma ini adalah menggunakan pendekatan Arsitektur Post-Modern dari Robert Venturi dan diharapkan Fasilitas ini dapat mewakili nilai lokalitas yang ada di Minahasa.
\end{abstract}

Kata Kunci : Wisma, Robert Venturi, Post-Modern

\section{ABSTRACT}

The purpose of this plan is to concentrate seminars, work visits, lodging and internship activities for students and for guests in general in one facility, namely the Wisma. The design method used in this study refers to the theory of the JC Glass box method. Jones in it is Macro Analysis, Micro Analysis, Structure and Utilities. The results of this planning are in the form of building designs that are displayed in the form of Site Plans, Floor Plans, Pieces, Views and Perspectives of the building. The conclusion of this Wisma planning is to use the Post-Modern Architecture approach from Robert Venturi and it is hoped that this facility can represent the locality values that exist in Minahasa.

Keywords: Wisma, Robert Venturi, Post-Modern 


\section{PENDAhUluan}

\subsection{Latar Belakang Masalah}

Selain menjadi tempat untuk menimba ilmu, Universitas Negeri Manado juga seringkali mengadakan kegiatan yang bersifat umum namun masih dalam lingkup pendidikan : seminar, kunjungan kerja dan lain-lain. Seringkali juga kegiatan-kegiatan tersebut mengundang tamu-tamu dari luar daerah untuk mengambil bagian dari kegiatan yang dimaksud. Disamping itu, ada beberapa kegiatan yang membutuhkan waktu beberapa hari sehingga para tamu harus mencari tempat penginapan untuk ditinggali selama berada di daerah UNIMA.

Fakultas Teknik Universitas Negeri Manado yang didalamnya ada jurusan Pendidikan Teknik Informatika, Pendidikan Teknik Bangunan, Teknik Sipil, Teknik Arsitektur, Pendidikan Teknik Mesin, Pendidikan Teknik Elektro, juga PKK (Pendidikan Kesejahteraan Keluarga), memiliki Mata Kuliah yang mewajibkan mahasiswanya untuk mendapatkan pengalaman kerja di perusahaan yang sesuai dengan jurusan yang diambil (magang).

Jurusan PKK juga didalamnya ada konsentrasi program studi Perhotelan dan Tata Boga, mewajibkan para mahasiswanya harus memiliki pengalaman kerja dengan perusahaan yang sesuai dengan jurusan yang diambil. Bagi para mahasiswa Perhotelan sudah tentu harus mendapatkan pengalamannya di hotel, begitu pula dengan mahasiswa Tata Boga harus mendapatkan pengalaman di restoran.

Pada zaman sekarang, selain menjadi kebutuhan, fasilitas umum merupakan hal yang penting untuk menunjang berbagai kegiatan manusia. Selain bisa mewadahi berbagai kegiatan, fasilitas umum juga harus memberikan kenyamanan bagi para penggunanya. Kenyamanan yang dimaksud yaitu : pelayanan yang baik, tampilan fasilitas yang bagus dan lain-lain yang dapat memberikan kenyamanan bagi para penggunanya. Agar para tamu tidak perlu menginap di tempat lain dan agar beberapa kegiatan yang diadakan oleh UNIMA : Seminar, kunjungan kerja tidak perlu diadakan di tempat lain dan agar para mahasiswa dari jurusan PKK tidak perlu kesulitan mencari perusahaan atau tempat untuk magang, dibutuhkan fasilitas yang dapat mewadahi kegiatan diatas. Selain itu, fasilitas tersebut juga harus dapat diakses dengan mudah. Karena memiliki lahan yang luas, UNIMA selayaknya dapat menyediakan fasilitas yang dapat mewadahi kebutuhan tersebut. Fasilitas yang dimaksud yakni, Wisma.

Sebagai pendekatan, rancangan ini menggunakan Pendekatan Arsitektur PostModern Robert Venturi. Pendekatan PostModern Robert Venturi adalah sebuah pendekatan arsitektur hybrid atau penggabungan antara dua hal yang tidak sama atau berbeda. Pendekatan ini digunakan karena, Indonesia sebagai negara yang memiliki adat dan suku bangsa yang beragam sudah pasti mempunyai gaya atau bentuk bangunan yang berbeda-beda. Setiap daerah mempunyai ciri khas dan bentuk bangunan yang unik. Di samping itu, perkembangan zaman juga melahirkan gaya arsitektur yang baru. Untuk menanggapi hal itu, pendekatan hybrid dari Robert Venturi dirasa tepat dengan menggabungkan gaya arsitektur tradisional Minahasa dan Modern.

\subsection{Tujuan dan Sasaran}

Tujuan perencanaan ini adalah untuk memusatkan kegiatan seminar, kunjungan kerja, penginapan dan kegiatan magang bagi mahasiswa serta bagi tamu pada umumnya dalam satu fasilitas yaitu Wisma, mewadahi aktivitas didalamnya dengan baik dan menerapkan konsep Wisma yang mengacu kepada konsep Arsitektur Post-Modern Robert Venturi.

Sasaran perencanaan ini adalah untukFasilitas Wisma yang yang nyaman dan baik dalam mewadahi aktivitas dan kegiatan didalamnya. 


\section{TINJAUAN PUSTAKA}

\subsection{Perencanaan}

Perencanaan dalam bahasa inggris disebut juga sebagai "planning”, dapat diartikan sebagai suatu sarana untuk mentransformasikan persepsi-persepsi mengenai kondisi-kondisi lingkungan ke dalam rencana yang berarti dan dapat dilaksanakan dengan teratur (William A.Shrode, 1974).

\subsection{Wisma}

\section{a. Pengertian Wisma}

Wisma menurut Kamus Besar Bahasa Indonesia, kata "wisma" memiliki dua arti: 1) bangunan untuk tempat tinggal, kantor dsb; 2) kumpulan rumah; kompleks perumahan; permukiman

\section{b. Jenis Wisma}

Wisma menurut Kamus Besar Bahasa Indonesia, wisma terdiri dari dua jenis: 1) cinta alam, merupakan bangunan yang diperuntukkan bagi pengunjung untuk dapat mengikuti kegiatan yang bersifat pendidikan konservasi; 2) tamu, merupakan rumah (gedung) khusus untuk tamu yang mungkin bermalam.

$$
\text { Berdasarkan tinjauan diatas, }
$$
dikaitkan dengan Perancangan Wisma Fakultas Teknik selanjutnya adalah sebagai berikut:

a) Sebagai sarana untuk memenuhi kebutuhan tamu sebagai tempat tinggal sementara.

b) Sebagai tujuan konferensi, seminar lokakarya, dan kegiatan serupa lainnya.

c) Sebagai tempat menambah ilmu pengetahuan dan pengalaman khusus bagi pelajar atau mahasiswa.

\subsection{Arsitektur Post-Modern Robert Venturi}

\section{a. Pengertian Arsitektur Post Modern} Arsitektur Post-Modern berkembang di akhir abad ke-20. Arsitektur
Post Modern merupakan gerakan arsitektur yang menyatu-padukan Art dan Science, Craft dan Technology, Internasional dan lokal yang merupakan hasil perkembangan sumber daya manusia terhadap arsitektur modern.

Hybrid adalah salah satu metode perancangan dalam sebuah karya arsitektur yang muncul di era Post Modern. Secara etimologis, Hybrid merupakan penggabungan beberapa aspek yang berbeda (binary oposisi), tentunya dalam bidang Arsitektur. Dalam perancangan arsitektur menggabungkan antara dua hal yan berbeda mungkin menjadi hal yang tidak asing. Karena di Indonesia konsep Hybrid ini dapat kita lihat di bangunan yang dimana menggabungkan antara Arsitektur Vernakular dengan Arsitektur Modern. Sehingga adanya penggabungan tersebut muncul sebuah konsep/ide gagasan yang baru yang menghasilkan sebuah karya berbeda.

b. Prinsip Desain Arsitektur Post-Modern Robert Venturi

Robert Venturi menyerukan sebuah "Hybrid Architecture" yang menggabungkan "masa lalu" dalam bentuk sejarah dan tradisional "kekinian" sebagai budaya popular, bahan bangunan modern (hi-tech) dan teknik. Dualitas ini menjadi kunci arsitektur Venturi. Dia lebih menyukai ruang sederhana modernisme karena dia melihat kebutuhan akan bangunan yang berantakan, jelek, kacau, membosankan, biasa, ikonis, ironis, dan double coded.

Pemikiran Robert Venturi tentang "Hybrid Architecture" terlihat di beberapa karyanya seperti Vanna Venturi House, Philadelphia (1964), Sainsbury Wing, National Gallery, Inggris (1991), Children's Museum, Texas (1992) dan Episcopal Academy Chapel, Pennsylvania (2008).

\section{METODE PENELITIAN}

3.1 Waktu dan Tempat Penelitian

Tempat yang akan digunakan untuk penelitian bertempat di daerah kampus Universitas Negeri Manado dan Fakultas 
Teknik. Waktu penelitian akan dimulai dari bulan Oktober hingga bulan November dan disesuaikan dengan jadwal dan jam kampus 3.2 Lokasi Penelitian

Lokasi penelitian yang akan digunakan untuk penelitian bertempat di daerah kampus Universitas Negeri Manado, Kecamatan Tondano Selatan, provinsi

Sulawesi Utara
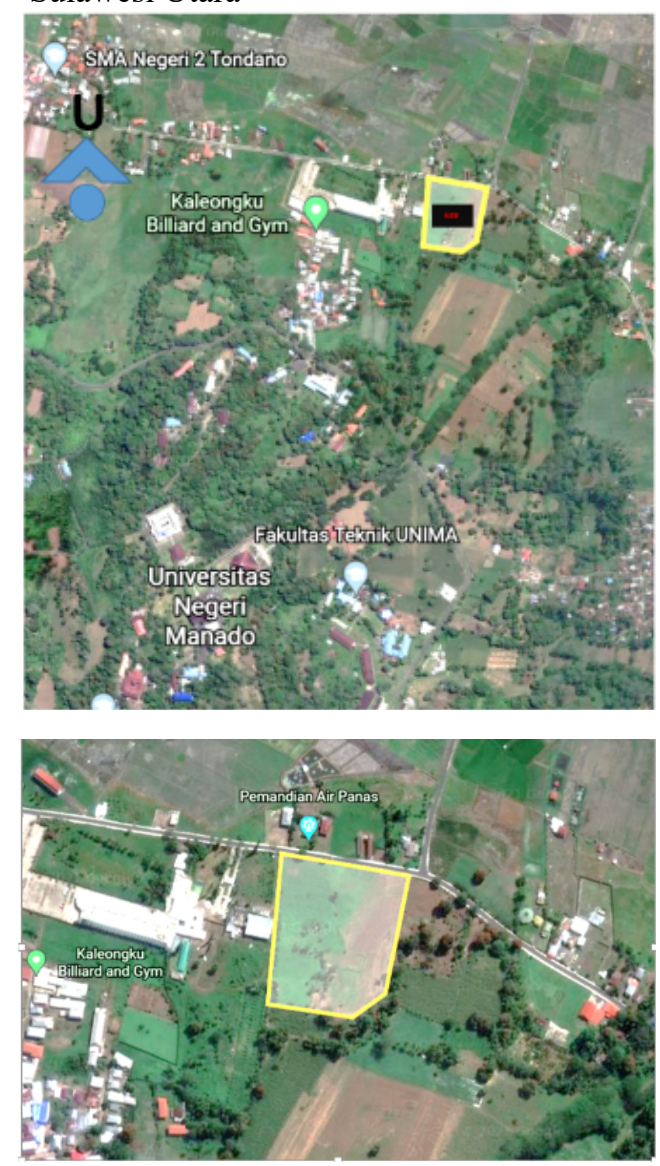

3.3 Metode Perancangan

Metode perancangan yang digunakan dalam penelitian ini mengacu pada teori Metode Glassbox JC. Jones dengan susunan sebagai berikut:

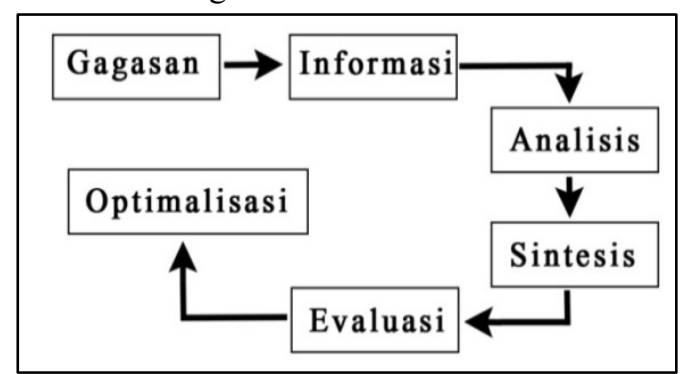

\subsection{Teknik Pengumpulan Data}

Untuk merencanakan dan merancang sebuah bangunan diperlukan bermacam - macam data yang relevan . Pengumpulan data akan dilakukan dengan menyesuaikan waktu dan jadwal kerja Universitas Negeri Manado. Adapun teknik pengumpulan data dilakukan adalah sebagai berikut:

\subsection{Survei}
a) Survei Lapangan
b) Survei Substansial

\subsection{Studi Literatur}

Disisi lain kebutuhan akan data yang sifatnya teoritik, referensi, dan studi kasus diperoleh melalui studi literatur sebagai rujukan. Literatur digunakan selama proses penyusunan konsep perencanaan dan perancangan.
3.7 Teknik Analisis Data
a. Analisis Makro
b. Analisis Mikro
c. Analisis Struktur dan Utilitas
d. Sintesis
e. Hasil Perancangan

\section{HASIL DAN PEMBAHASAN}

\subsection{Analisis Makro Lokasi Perancangan}

Lokasi perancangan bertempat di

Tondano Selatan, Kabupaten Minahasa. Untuk lebih tepatnya disamping Hotel Yama 4.2 Pemilihan Site

Pemilihan site dilakukan dengan mempertimbangkan beberapa faktor, yakni:

a) Berada di area kampus (Universitas Negeri Manado).

b) Lokasi dilalui oleh kendaraan atau jalur transportasi.

c) Lokasi mudah diingat dan dikenal oleh pengunjung.

d) Lokasi cukup dekat dengan Kantor Pusat Universitas Negeri Manado. 
Jurnal Gearbox Pendidikan Teknik Mesin ISSN 2774-7697 (media online)

Volume 2 Nomor 2, Desember 2021 Hal. 90-97

http://ejurnal-mapalus-unima.ac.id/index.php/gearbox

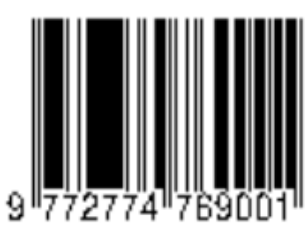

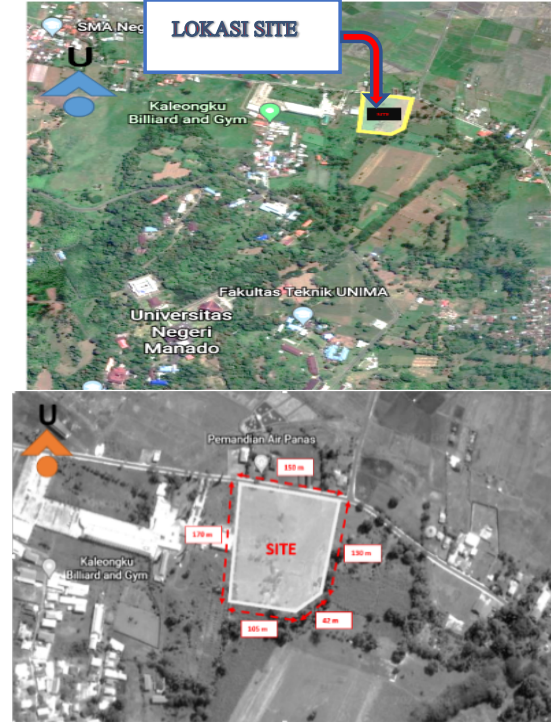

Ukuran Site adalah $25.500 \mathrm{~m}^{2}$.

\subsection{Analisa Tapak}

a. Kontur Tanah

Site merupakan tanah yang baik dengan kemiringan $\pm 5^{\circ}$ ( tiga derajat) dan titik tertinggi di tapak $16 \mathrm{~m}$.

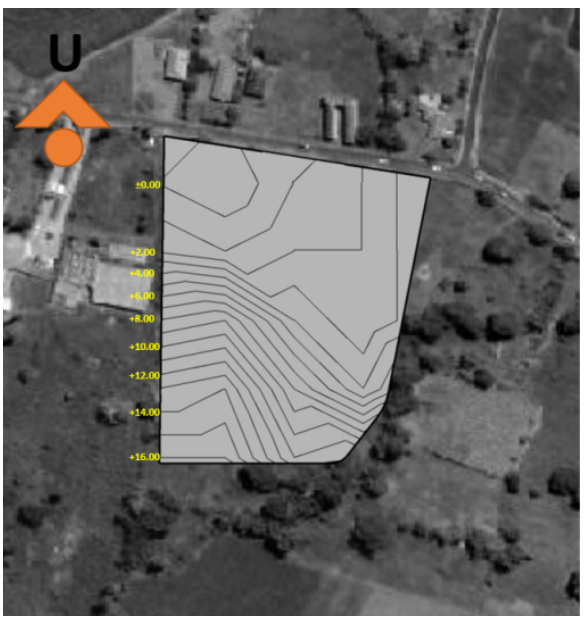

b. Drainase

Saluran drainase berada didepan tapak juga menjadi saluran utama untuk saluran

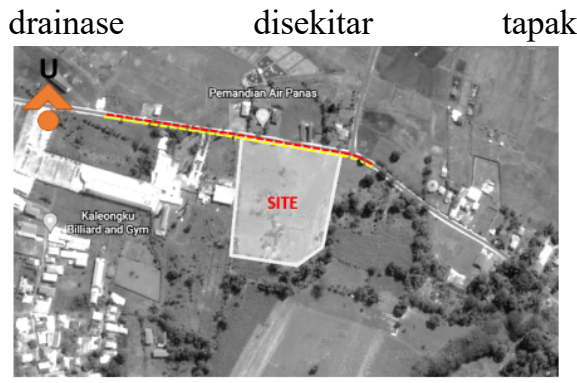

c. Sirkulasi

Site bisa diakses dari jalur utama sehingga site dapat diakses dengan mudah oleh pejalan kaki kendaraan dari jalur utama. Yang menjadi kekurangan adalah tidak ada semacam penghubung seperti jembatan kecil yang menghubungkan site dengan jalan utama karena ada saluran

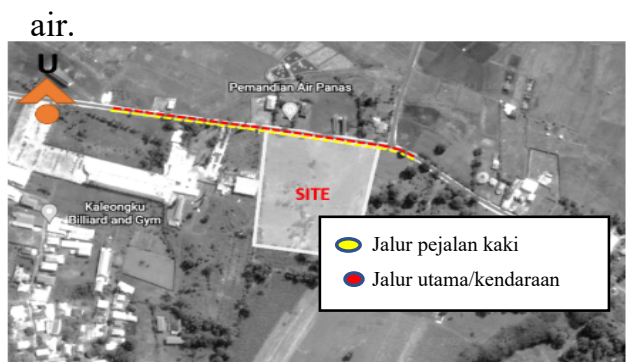

d. Vegetasi

Vegetasi didalam tapak tidak terlalu banyak hanya terdapat beberapa pohon, semak dan jagung.

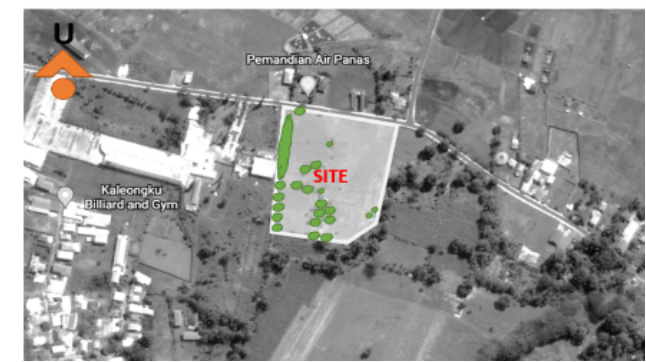

e. Kebisingan

Kebisingan didalam tapak tidak terlalu tinggi karena lokasi tapak jarang dilalui oleh kendaraan dari jalur utama.

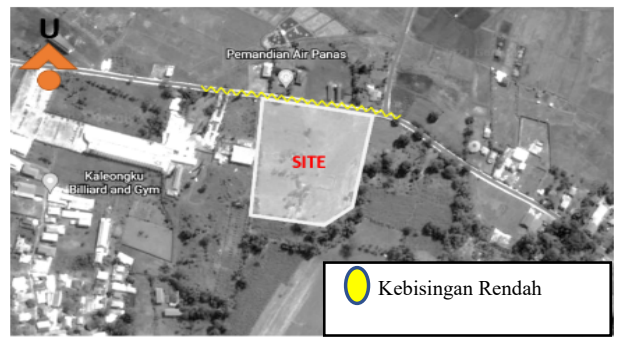

f. View

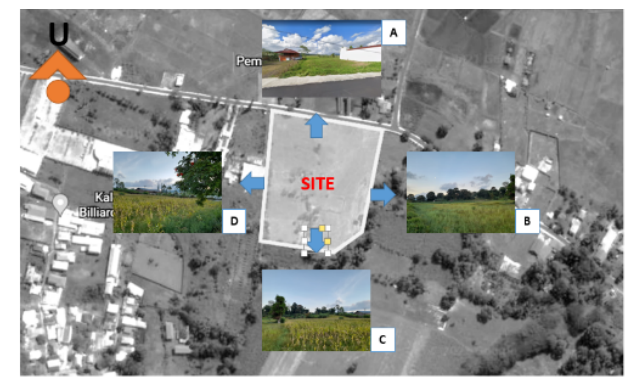


Jurnal Gearbox Pendidikan Teknik Mesin ISSN 2774-7697 (media online)

Volume 2 Nomor 2, Desember 2021 Hal. 90-97

http://ejurnal-mapalus-unima.ac.id/index.php/gearbox

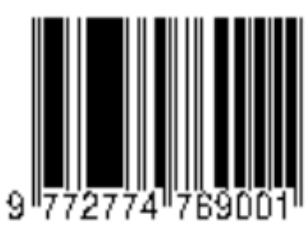

a) View ke arah Utara

b) View kearah Timur

c )View ke arah Selatan

d) View ke arah Barat

\section{g. Arah Angin}

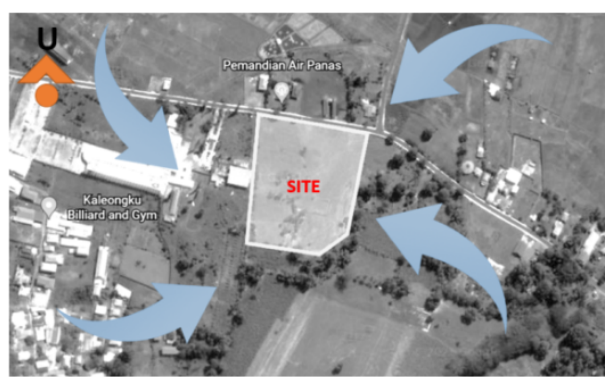

h. Orientasi Matahari

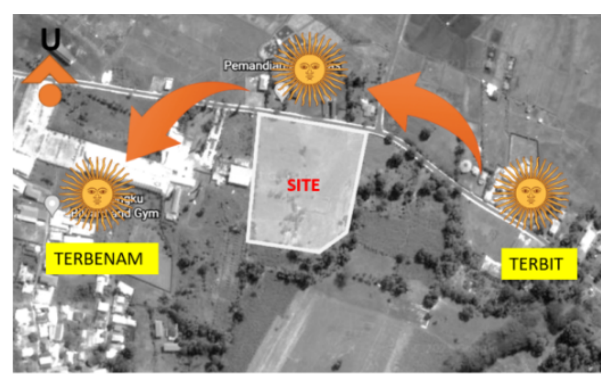

\subsection{Studi Bentuk Bangunan}

Berdasarkan analisa sebelumnya, maka bentuk bangunan yang didapatkan adalah sebagai berikut.

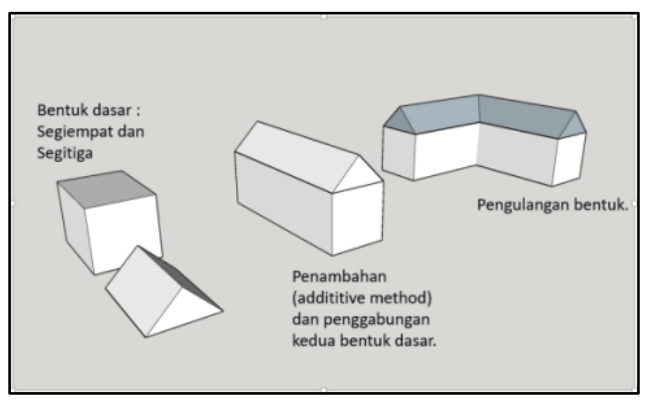

Bentuk diatas juga diadaptasi dari bentuk rumah minahasa yang memiliki bentuk dasar segitiga dan segiempat.

\subsection{Hasil Perancangan}

Site Plan

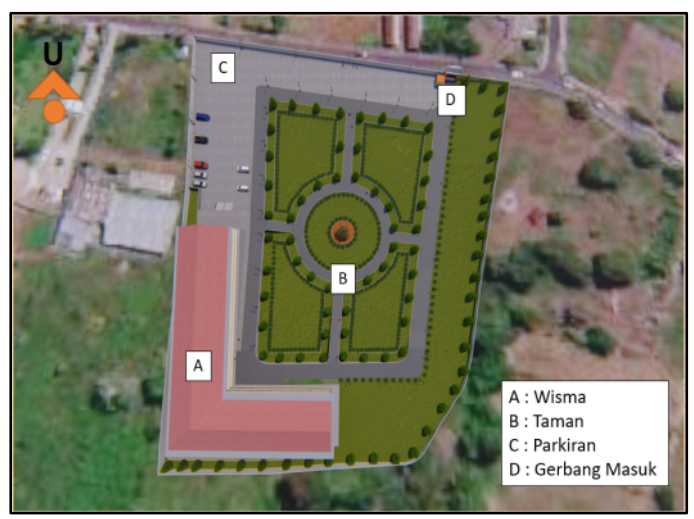

Denah Lantai 1

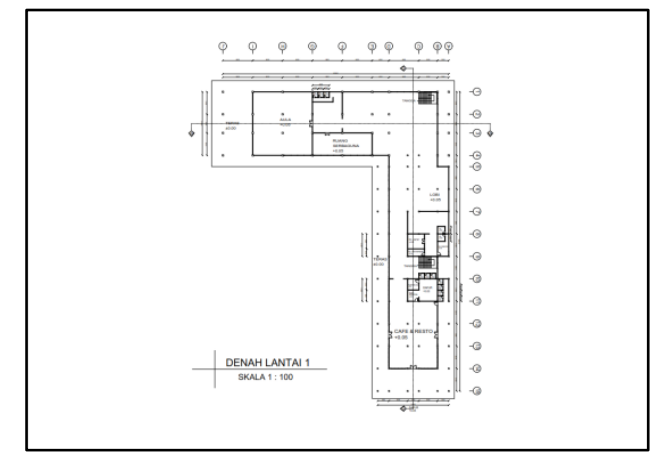

Denah Lantai 2

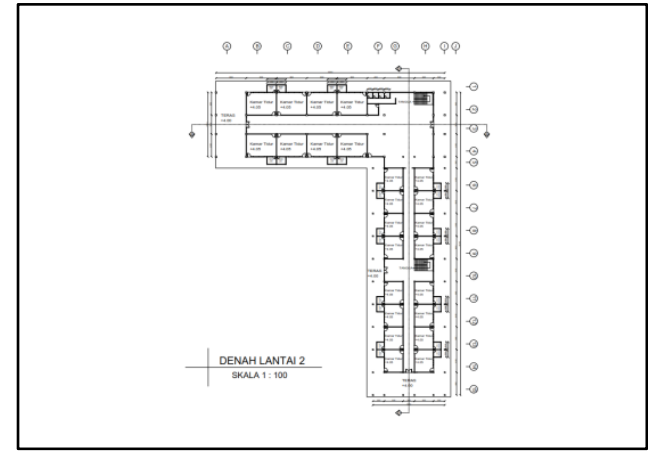

Denah Lantai 3

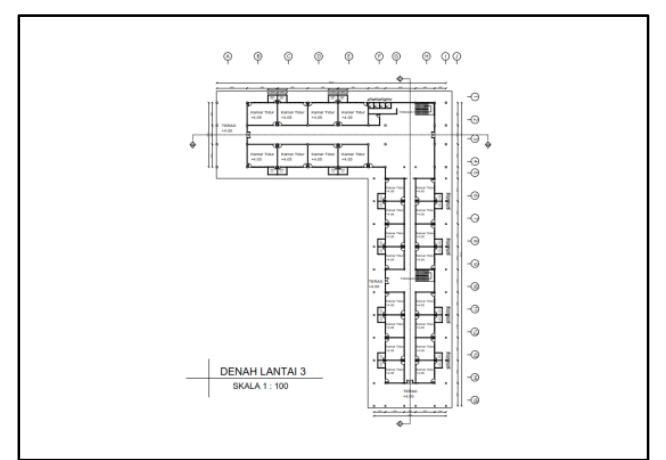


Jurnal Gearbox Pendidikan Teknik Mesin ISSN 2774-7697 (media online)

Volume 2 Nomor 2, Desember 2021 Hal. 90-97

http://ejurnal-mapalus-unima.ac.id/index.php/gearbox

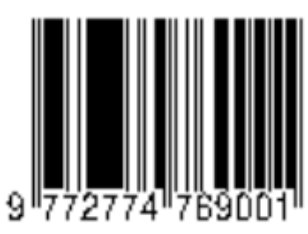

Tampak Depan

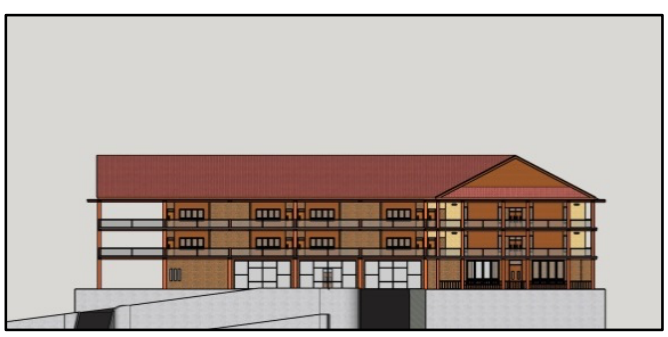

Tampak belakang

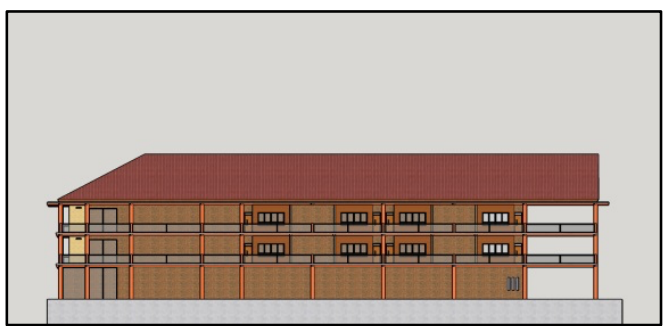

Tampak Samping Kanan

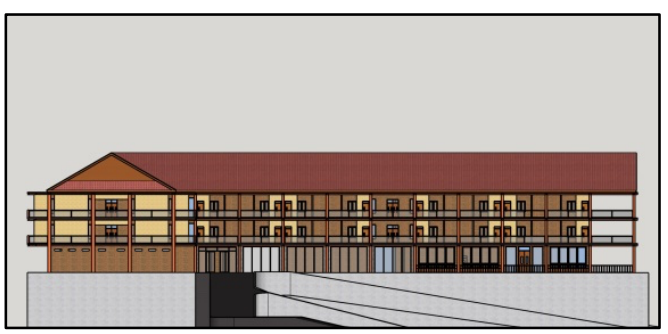

Tampak Samping Kiri

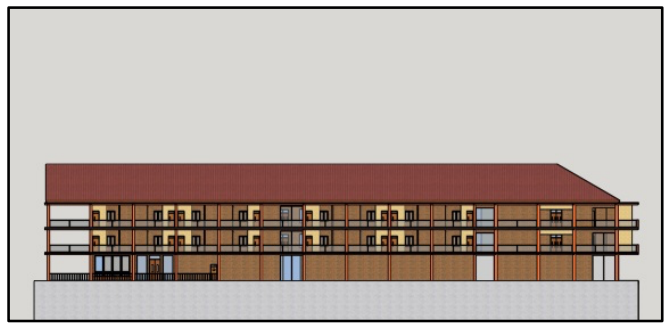

Perspektif 1

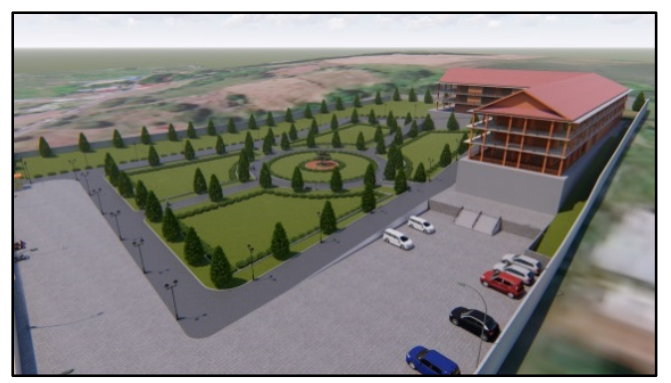

\section{Perspektif 2}

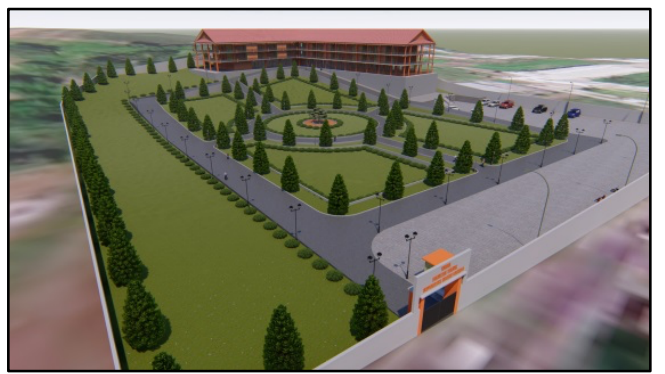

\section{Perspektif 3}

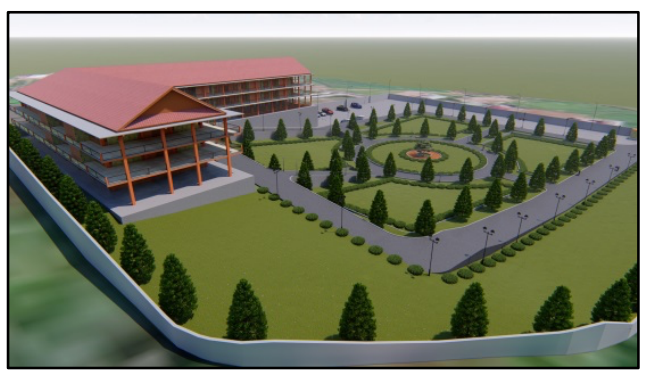

\section{Perspektif 4}

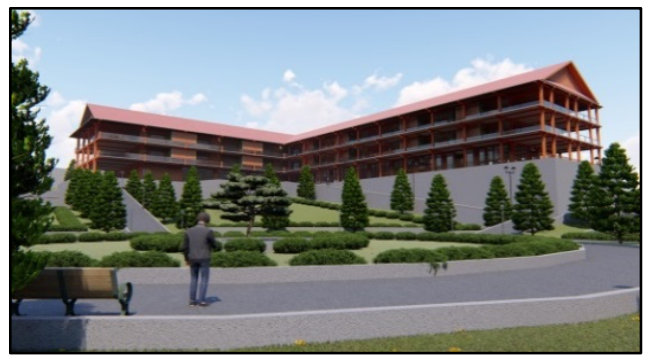

Perspektif 5

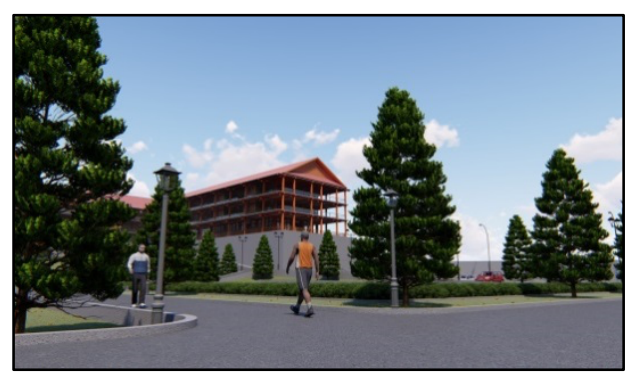

Perspektif 6

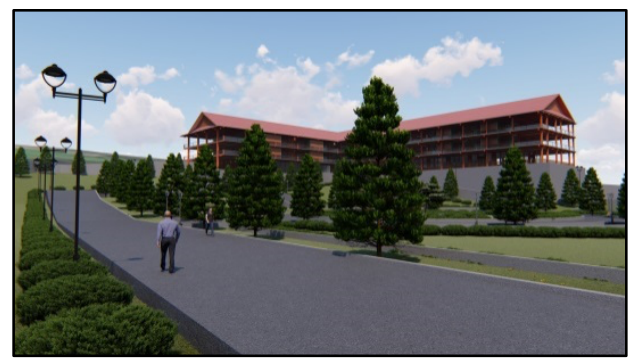


Jurnal Gearbox Pendidikan Teknik Mesin ISSN 2774-7697 (media online)

Volume 2 Nomor 2, Desember 2021 Hal. 90-97

http://ejurnal-mapalus-unima.ac.id/index.php/gearbox

\section{KESIMPULAN DAN SARAN}

\section{Kesimpulan}

Perencanaan dan Perancangan Wisma Fakultas Teknik Dengan Pendekatan Arsitektur Post-Modern Robert Venturi di Universitas Negeri Manado merupakan sebuah wadah representatif untuk berbagai kegiatan yang ada di Universitas Negeri Manado seperti, kegiatan seminar, pendidikan, konservasi, magang dan penginapan. Dengan adanya Fasilitas ini diharapkan bisa mewadahi berbagai kegiatan diatas. Selain itu, penginapan didalam wisma ini juga terbuka untuk masyarakat umum sehingga bisa menjadi daya tarik tersendiri bagi Universitas Negeri Manado.

Dengan menggunakan pendekatan Arsitektur Post-Modern dari Robert Venturi diharapkan Fasilitas ini dapat mewakili nilai lokalitas yang ada di Minahasa. Pendekatan Hybrid oleh Robert Venturi yaitu menggabungkan antara dua gaya arsitektur menjadi satu, dalam perancangan Wisma Fakultas Teknik ini menggabungkan antara Modernitas dan Lokalitas budaya minahasa yaitu gaya Rumah Adat Minahasa untuk menjadi bentuk bangunan yang hendak dicapai.

\section{Saran}

Dalam proses penyusunan Skripsi ini masih banyak kekurangan yang dimiliki penulis, maka dari itu diharapkan saran agar supaya bisa lebih baik lagi kedepannya dan tentunya untuk perkembangan bidang arsitektur itu sendiri juga.

Harapan penulis ialah agar Skripsi Perencanaan dan Perancangan Wisma Fakultas Teknik Dengan Pendekatan Arsitektur Post-Modern Robert Venturi di Universitas Negeri Manado ini selain dapat bermanfaat untuk bidang pendidikan, juga agar bisa dijadikan bahan kajian dan dikembangkan lebih lanjut

\section{DAFTAR PUSTAKA}

Dimarsitek. Pemikiran Arsitek (Robert Venturi).https://dimarsitek.wordpre ss.com/?s=pemikiran + arsitek $+\% 2$ 8robert+venturi\%29

F.X. Budi Widodo dan Y. Roni Sugiarto. 2014. Teknik Pendekatan Desain Bentuk Estetik Arsitektural. Yogyakarta : PT. Kanisius

Google Earth

Neufert, Ernst. 1996. Data Arsitek Jilid 1. Jakarta : Erlangga

Neufert, Ernst. 2002. Data Arsitek Jilid 2. Jakarta : Erlangga

Urbanmonkees.bloq. Arsitektur Post Modern.https://virtualarsitek.wordp ress.com/artikel/sejaraharsitektur/tipologiarsitektur/arsitektur-post-modern/

Wikiarquitectura. Sainsbury Wing, National Gallery.https://en.wikiarquitectura com/building/sainsbury-wingnational-gallery/

- Wikipedia. Guild House. https://en.wikipedia.org/wiki/Guild House_(Philadelphia)

- Shrode, William, A., dan Dan Voich, J. 1974. Organization and Management : Basic System Concepts, Irwin Book Co. Kuala Lumpur 